\title{
Multifocal T2-/DWI-hyperintense cerebral lesions in COVID-19 not necessarily imply demyelination
}

\author{
Lesões cerebrais multifocais hiperintensas em T2/DWI na COVID-19 não implicam \\ necessariamente em desmielinização
}

Josef FINSTERER1, Fulvio Alexandre SCORZA², Carla Alessandra SCORZA², Ana Claudia FIORINI2,3

\section{Dear Editor,}

With interest, we read the article by Pessoa Neto et al. about a 49-year-old male with COVID-19 in whom multiple T2- and diffusion-weighted imaging (DWI) hyperintense lesions were detected after 19 days on mechanical ventilation ${ }^{1}$. The multilocal cerebral lesions were interpreted as demyelinating in nature. The study evokes some comments and concerns.

The main shortcoming of the study is that the cerebral lesions were interpreted as "demyelinating", without substantial proof for this speculation. Arguments in favor of the "demyelinating" hypothesis are that the lesions disappeared under immunosuppression with steroids and were T2-hyperintense. However, resolution under steroids could also be an accidental event. A strong argument against "demyelination" is that the lesions did not enhance under gadolinium use. Differential diagnoses to be considered include multiple, embolic, ischemic stroke, multifocal posterior reversible encephalopathy syndrome (PRES), acute demyelinating encephalitis (ADEM), multifocal encephalitis, acute hemorrhagic necrotizing encephalopathy (AHNE), or multi-local stroke-like lesions (SLLs). In order to further elucidate the nature of these lesions, it is crucial that the patient undergoes cerebrospinal fluid (CSF) investigations, particularly to check for pleocytosis, oligoclonal bands, or IgG elevation. The results of susceptibility weighted imaging (SWI) and magnetic resonance spectroscopy (MRS) should also be presented, particularly whether there was a lactate peak or not.
A further shortcoming of the study is that no information was provided about other magnetic resonance imaging (MRI) modalities besides T2, DWI, and T1 with contrast medium. One should be informed about the results of the apparent diffusion coefficient (ADC) maps, perfusion-weighted imaging (PWI), SWI sequences, and oxygen extraction fraction (OEF) MRI. Since the lesions could also be interpreted as subacute embolic stroke, it is important to know whether there was hypercoagulability or risk factors for embolic stroke, such as atrial fibrillation, heart failure, non-compaction, or intra-ventricular or atrial thrombus formation, as previously reported in COVID-19 patients².

The patient was described with quadriparesis and generally reduced tendon reflexes 19 days after admission ${ }^{1}$. The results of nerve conduction studies (NCS) and needle electromyography (EMG) should be provided. It should be clarified if the patient simultaneously presented with cerebral lesions and Guillain Barre syndrome, which is increasingly recognized as a manifestation of neuro-COVID 3 . Differentials such as critical ill neuropathy, critical ill myopathy, myasthenia, or pre-morbid polyneuropathy should be excluded.

Overall, the interesting case report has a number of shortcomings which should be addressed in order to draw final conclusions. Particularly, results of CSF investigations, SWI, OEF, PWI, ADC modalities of multimodal MRI, results of NCS, and EMG findings should be provided.

\footnotetext{
${ }^{1}$ Klinik Landstrasse, Messerli Institute, Vienna, Austria.

¿Universidade Federal de São Paulo, Escola Paulista de Medicina, Disciplina de Neurociência, São Paulo SP, Brazil.

${ }^{3}$ Pontifícia Universidade Católica de São Paulo, Programa de Estudos Pós-Graduado em Fonoaudiologia, São Paulo SP, Brazil.

Josef FINSTERER (iD https://orcid.org/0000-0003-2839-7305; Fulvio Alexandre SCORZA (iD https://orcid.org/0000-0002-0694-8674;

Carla Alessandra SCORZA (D) https://orcid.org/0000-0001-7810-4748; Ana Claudia FIORINI (iD https://orcid.org/0000-0003-2989-2308

Correspondence: Josef Finsterer; E-mail: fifigs1@yahoo.de
}

Conflict of interest: There is no conflict of interest to declare.

Authors' contributions: JF: design, literature search, discussion, first draft, and critical comments. FS, CS, and AF: literature search, discussion, critical comments, and final approval.

Received on October 29, 2020; Accepted on October 31, 2020. 


\section{References}

1. Pessoa Neto AD, Alves MDM, Brito PSM, Moreira Neto M, Silva RAE, Teixeira Dourado ME, et al. Possible acute multifocal demyelinating lesions in a COVID-19 patient. Arq NeuroPsiquiatr. 2020 Oct;78(10):666. https://doi.org/10.1590/0004$282 \times 20200126$
2. Shamsah MA, Bitar ZI, Alfoudri H. Right atrial thrombus in a patient with COVID-19 pneumonia: a case report. Eur Heart J Case Rep. 2020 Sep;4(FI1):1-4. https://doi.org/10.1093/ehjcr/ytaa296

3. Finsterer J, Scorza FA, Fiorini AC. SARS-CoV-2-associated GuillainBarre syndrome in 62 patients. Eur J Neurol. 2020 Oct:10.1111/ ene.14544. https://doi.org/10.1111/ene.14544 